\title{
Discurso de paranympho do Dr. Spencer Vampré, na collação de gráu dos bacharelandos de 1925.
}

Meus jovens Amigos

Como sois differentes de quando aqui entrastes, calouros espavoridos ante a imaginaria crueldade dos veteranos, muitos dos quaes já partiram, como partis hoje, para as batalhas da vida!

Desabrochastes a alma nestes cinco annos, como a rosa desabrocha ao frescor do orvalho, e se faz perfume e côr, e pompeia mimosa e soberana.

Acordastes para a sciencia e para o amor, para a literatura e para o sonho, para a arte e para a vida, e vos sentistes de repente homens, com a mesma alviçareira alegria com que a chrysallida rompe o casulo, e, já borboleta, esvoaça pelo azul, descuidosa de perigos, e sobe e desce, e anceia e palpita, e adeja em milagres de colorido, desdobrando ao sol o iris das asas polychromas. Assim vós, assim vós, borboletas inquietas, em bando sussurrante desferis agora o vôo 
por montes e valles, por quebradas e serras, por alturas e barrancos, já libradas sobre a face bisbilhante dos regatos, já tontas de luz e enxovalhadas de pollen, na orgia carnavalesca dos jardins em flôr.

Sêde bemdictos, amigos! Que a fortuna vos guie, e que as tres deusas olympicas desta Academia vos encaminhem pelas estradas!

Os que cruzam, lá de fóra, este velho largo de São Francisco, na faina das lides materiaes, na ambição metalisadora da vida paulista; os que desandam a correr á caça do ouro, e passam, inconscientes e cegos, ante os portaes resplendentes desta casa, não sentem jorrar daqui esse facho de luz intensa, que ha quasi cem annos vem clareando e illuminando os destinos do Brasil; não percebem, miseros, o esplendor sagrado desta cathedral pagan, cujos ritos possuem, entretanto, a pureza eterna, a solennidade religiosa da symbologia do Christianismo.

Moram aqui, amedrontadas da impureza dos tempos e fugidas á ingratidão dos homens, tres deusas mythologicas, tres potestades immortaes, a cujos influxos magicos obedecem os destinos deste templo. Essas tres deusas vos receberam aqui ha cinco annos, e vos presidem ainda agora á partida, invisiveis, porém reaes, - mas além, muito além da esphera grosseira dos sentidos, num mundo de vibrações e de côres, de sons e de aromas, de harmonias infinitas, de orchestrações insondaveis, tão sublimes que o nosso pobre espirito nem logra cogitar.

Diz-vos a primeira: - Recordaes-vos quando, ha um lustro, vos encaminhastes para estas paragens? Ereis pouco mais que meninos, e agora sois homens feitos. Nada sabieis dos segredos mysteriosos da sciencia, e das dolorosas realidades da vida. Quando surgistes, o sonho vos nimbava as cabeças de talento e de vigor.

Sem que o. soubesseis, fui eu quem vos inspirou os enthusiasmos ruidosos com que enchieis de alegria e de troça estas vetustas arcadas, no borborinho de todas as manhans, quando os sinos tangiam para as aulas, e passavam os lentes, ou 
graves ou risonhos, entre as alas que abrieis, emmudecendo os risos e escondendo os cigarros.

Fui eu quem vos semeou no coração o que de mais puro e mais generoso possa conter - o sentimento cavalheiresco e profundamente humano com que, em impetos altruisticos, amparaes os que soffrem e sorris aos que padecem.

Fui ainda eu quem vos instillou a paixão da sciencia e da patria, e vos reverberou no coração o esplendor da fé, e vos germinou no cerebro a dedicação pelo estudo.

Fui ainda eu. . Mas, quem és, tu, deusa sublime, e porque te escondes nesta clamyde invisivel e purissima, de cujas dobras brotam jorros de luz? Dize o teu nome, deusa compassiva!

E ella, abrindo-vos os braços, mais formosos que os de nenhuma mulher do ceu ou da terra; ella, descerrando-vos o seio, mais virginal do que o de nenhum ser existente, ou possivel; ella, offerecendo-vos o labio, cheio de beijos, mais ardentes e mais doces que quantos beijos homens ou deuses hajam sonhado, - responde singelamente: - "eu sou a Mocidade, a primavera do mundo do espirito, como a primavera é a mocidade do mundo physico; uma e outra rebentos da mesma arvore, pomos dourados do mesmo galho, que a mão da Providencia estendeu sobre os caminhos dos homens.

Mas, ao passo que a primavera renasce, cada anno, no gorgeio dos passaros que cantam, no mimo das flôres que trescalam, na pujança da seiva que circula, no rocio das madrugadas que acordam o silencio das matas e a agitação febril das cidades; - ao passo que ella torna, generosa $\mathrm{e}$ gentil, em cada anno, na majestade de suas graças, a Providencia liberal, mas ciosa, só me concede a mim (ai! de vós, oh! homens!), só me concede uma unica vez a cada um! $\mathrm{E}$ a estas palavras merencoreas, que vos cortam a alegria, qual um relampago numa noite serena de Agosto, inclinaes a cabeça entristecida.

Mas, uma outra sombra, indecisa, se corporifica; um feminino corpo nasce da penumbra; o collo ondeia, o cabello 
cae em flocos; as feições se accentuam, em grega correcção de linhas. $E$ os braços se arqueiam, e arfa o seio, e as pernas descem, com a graça e a leveza corinthias. E toda uma mulher se destaca, não de marmore, senão viva e palpitante, com a rubra carnação em contraste ao verde claro das roupas.

Quem és tu, mysteriosa apparição? Que Deus poderoso, ou que demonio perverso, synthetisa em ti todas as maravilhas da natureza, e te faz divindade real, ou mystificação dos sentidos, tão formosa e tão louçan?

- "Eu sou a Esperança. Não me vistes, moços, quando єntraste aqui, da primeira vez; mas, dentre as minhas irmans, fui eu quem vos enlaçou primeiro nestes corredores, e os beijos que sentistes em sonho, e os anceios que sonhastes accordados, e o ninho verdejante de amor que imaginastes, e a terna desposada, em cujo seio ides dormir daqui ha uma hora, todo esse mundo radiante de chiméra, todo esse fantastico universo que vos brilha nas pupillas, tudo isso nasceu ao toque magico de meu condão, porque eu sou a Esperança, irman da Mocidade, e com ella, deusa vestal desta Academia.

Nas horas de desespero e de febre, quando o espirito, impotente ante as difficuldades da sciencia, ou o animo debilitado aos embates da vida, vos inclinou a cabeça para o chão e os braços cansados da luta descahiram na renuncia dos vencidos; quando pensastes em morrer, em desertar da vida, amarga como a cicuta; quando a maldade ou a indifferença, vos encheram de demonios o coração e os incubos da noite dansaram dentro de vossa alma em sarabanda infernal, celebrando festins de odio e de fel; no fundo da mente combalida, entre os cardos sangrentos do coração febricitante, não sentistes, delicada e longinqua, uma voz interior, que era apenas um balbucío, e logo um sussurro, e depois um rugido, um clamor, um grito enthusiastico, um impeto generoso, que vos sacudiu da cabeça aos pés? Pois, esse balbucio, esse sussurro, esse éco, esse despertar da alma, era 
eu, era a Esperança, envolvendo-vos todos no manto verde do sonho.

E a cabeça se vos alteou com a coragem dos fortes e a alegria dos heroes; e tomastes de novo os livros de sobre a mesa, e a lampada nocturna rebrilhou mais ante vossos olhos do que a Via Lactea, e todo um mundo infinito de constellações se vos desdobrou nos horizontes da vida."

$\mathrm{E}$ a estas palavras taes, sentis, moços, que tendes esperanças, e que sereis vencedores.

Mas, quem é esta outra visão subtil, toda envolta no manto lilaz da dôr? Porque vens, com os olhos lacrimosos, visão triste e soffredora, nesta hora feita de luzes e de festas? Porque bates á nossa porta, tão de manso e tão a medo, como só o fazem os mendigos, os santos, e as crianças?

Quem és tu, fantasma ou apparição de outras éras, ser de outro mundo, ente de plagas desconhecidas e estranhas, a cuja presença o nosso coração suspira e treme, e a cujo aspecto os olhos se nos maream?

E ella, levantando para nós o olhar piedoso e triste, nos responde: - "Ai! eu sou a Saudade, a companheira eterna dos que alisaram estes bancos; dos que ouviram estes mestres; dos que riram nestes gracejos juvenis; dos que gargalharam nestes corredores; dos que escreveram os palimpsestos da troça nestas paredes; dos que esculpiram nestes bancos a irreverencia de seus nomes, emquanto os mestres, graves na cathedra, destrinçavam os textos das leis e as controversias dos doutores.

Eu sou Castro Alves e Fagundes Varella; e Alvares de Azevedo e Vicente de Carvalho; e Ricardo Gonçalves e Cepelos; e Raymundo Corrêa e Olavo Bilac, - porque sou a poesia.

Eu sou Gabriel dos Santos e João Monteiro; e Brasilio Machado e Leoncio de Carvalho; e José Bonifacio e Joaquim Nabuco; e Cesar Bierrembach e Ruy Barbosa, - porque sou a eloquencia.

Eu sou João Mendes e Pedro Lessa; e Chrispiano e Al- 
meida Nogueira; e Duarte de Azevedo e Ribas; e Teixeira de Freitas e Pimenta Bueno, - porque sou o direito.

Poesia, eloquencia, direito, - eu, - a saudade, - sou tudo isso, porque tudo isso é o passado desta Academia, o escrinio de suas glorias, o padrão de seus feitos.

Agora, nós, como Páris, a entregar o pomo de ouro á formosa das tres divindades pagans, hesitamos já, absortos na contemplação e enlevados na magia de cada uma, a qual das tres potestades desta casa - á Mocidade, á Esperança ou á Saudade, possa caber a primasia.

Numa destas noites, cansado das canseiras da vida, procurava no silencio dos meus livros o refrigerio que nos nega a frequencia do mundo, e não sei porque artes me puz a excogitar a qual dessas tres Graças, acaso escolheria eu, si pudesse, para dizer-vos neste momento uma palavra amiga, toda de carinho e de fé, de recordação desse triennio em que estudámos juntos, e em que eu senti tantas vezes o vosso coraçãozinho de moços palpitar junto ao meu.

Não sei si o somno me entorpeceu os membros. Sim. Foi sonho com certeza; porque miragens taes somente o sonho as póde gerar. Tudo era treva a principio. De repente um clarão, como quando o carro da aurora aponta no Oriente, e os passaros saudam o primeiro raio de sol. Em momentos, toda a esphera celestial se illuminou, como numa aurora boreal. E os tres vultos de peregrina belleza:um, alvissimo como o alabastro; outro, verde como mar, outro, roxo como as violetas, encheram-me o horizonte visual, e todo me fascinei nesta visão como os beatos do Paraiso.

Eram os mesmos numes desta Academia: - a Mocidade, a Saudade e a Esperança.

$\mathrm{E}$, enlaçadas, deixaram cahir estas vozes: - "A mocidade é o presente, porque resurge, cada anno, nos estudantes novos, como a primavera accorda, após o rigor do inverno, as forças virgens da natureza.

Não vês como a Academia fica enregelada e fria nas 
férias, quando as avezinhas desfecham o vôo em busca de outros climas?

A Esperança é o futuro, o futuro da sciencia, o futuro da Patria: quando a sciencia não mais armar povos para a guerra, mas se assentar de verdade nos Congressos da Paz; quando a Patria se não degladiar em luctas fraticidas, mas unir-se na licção das virtudes democraticas; quando o Brasil não conhecer mais estados de sitio, nem proscripções, e quando cada um de nós puder ter o orgulho de pertencer à mais perfeita democracia da Terra.

A Saudade é o passado, o passado que nos conduz para a Mocidade, e para a Esperança, como o dia de hontem conduz para o dia de hoje, e para o de amanhan.

Vae, professor humilde, sagrado hoje pela escolha de teus discipulos, que o são tres vezes pelo triennio em que os ensinastes, e que o são ainda tres vezes pelo amor á Sciencia, á Patria e á Academia; vae, e dize-lhes, ainda que em rude e desataviado discurso, esta mensagem que cada uma de nós lhes manda".

E a Mocidade falou: - "Dize-lhes que sejam eternamente moços, da mocidade immortal do espirito, e que, quanto mais envelheçam, mais remocem, pelo ideal e pela fé, pelo amor ao Brasil, pelos impetos bons e cavalheirosos, que não conhecem castas nem riquezas, nem poderios, nem raças, nem credos. Dize-lhes que o advogado é tão poderoso, sobre a face da terra, que não precisa de protectores; mas que tambem é tão fraco, que não logra ter protegidos; que é tão altivo, que perante elle se inclinam as majestades da terra, mas tão humilde que se inclina e reverencia as verdadeiras majestades, - a virtude, o talento, a justiça e a verdade.

Dize-lhes que o advogado a ninguem teme; mas, por isso mesmo, jamais desce á intriga, ao insulto, á mentira, á bajulação, miserias moraes, e derradeiro valhacouto dos covardes.

Dize-lhes que respeitar o adversario, e usar de armas leaes, é o primeiro dever do advogado, que a si mesmo se 
respeita, respeitando o magestade da lei; que cada pleito é um exemplo á sociedade, e que cada acto do advogado é patrimonio moral da cidade, do Estado, da Nação inteira. Dize-lhes ainda que amparar o fraco, proteger a viuva, cobrir a nudez ao orpham, dar um pedaço de pão a quem tem fome, dar de beber a quem tem sêde, tudo isso são deveres do advogado, porque tudo isso é sentir impulsos juvenis no coração e no espirito.

Dize-lhes, em uma palavra, que sejam moços, sempre moços, incorruptivelmente moços, isto é, nobres, desinteressados, altivos e grandes".

Isto falou a Mocidade, e desappareceu, como nuvem branca aos raios quentes do sol.

E a Esperança falou assim: - "Dize-lhes que tenham esperanças; que esperem e creiam no progresso indefinido da sciencia, na perfectibilidade progressiva das instituições juridicas e sociaes; que esperem e lutem por uma sociedade melhor em que o homem, mais illuminado pela fé scientifica e mais confortado pela fé religiosa, comprehenda melhor os mysterios do mundo, e se aproxime um pouco da face do Criador.

Dize-lhes que anceiem pela hora em que o espirito humano, clareado pela sciencia, tenha fé e confie, porque a sciencia, obra prima da Divindade, não pode ser a contradição de sua omnipotencia.

Queria a Esperança falar ainda, quando a interrompeu a Saudade: - Dize-lhes que levem gravada no mais fundo do coração a imagem da Academia, onde nasceram outra vez, porque aqui nasceram para vida do sentimento e para a vida das idéas, porque aqui sentiram o primeiro anceio de amor e a primeira comprehensão das coisas.

Dize-lhes que recordem, num instante de religioso recolhimento, os collegas que lá ficaram, em meio da jornada, e os mestres queridos que a Morte ceifou com o seu alfange.

Dize-lhes que visitem sempre, nas romagens do espirito, estas arcadas seculares, onde se lhes apegaram fragmentos 
da alma, farrapos das alegrias e das dores de outrora, a lhes acenar de longe, como lenços brancos que se agitam".

Isso, disse a Saudade. E quando eu lhe quiz falar, desappareceu subitamente, e com ella a Esperança.

$\mathrm{E}$ eu me vi, meus queridos amigos, só, e pobre de graças, á beira da estrada em que ieis passar, sem ter ao menos um punhado de flores com que vos alcatifasse o caminho. Como poderá o meu pobre linguajar traduzir tantas pompas?

Não! Não vos posso dizer nada.

Bôa viagem! Que as tres deusas amigas vos acompanhem, vos confortem e vos protejam. 